\title{
Summary of Guidance for Public Health Strategies to Address High Levels of Community Transmission of SARS-CoV-2 and Related Deaths, December 2020
}

\begin{abstract}
Margaret A. Honein, $\mathrm{PhD}^{1}$; Athalia Christie, MIA ${ }^{1}$; Dale A. Rose, $\mathrm{PhD}^{1}$; John T. Brooks, $\mathrm{MD}^{1}$; Dana Meaney-Delman, MD ${ }^{1}$; Amanda Cohn, MD ${ }^{1}$; Erin K. Sauber-Schatz, $\mathrm{PhD}^{1}$; Allison Walker, $\mathrm{PhD}^{1}$; L. Clifford McDonald, MD ${ }^{1}$; Leandris C. Liburd, PhD ${ }^{1}$; Jeffrey E. Hall, PhD ${ }^{1}$; Alicia M. Fry, MD ${ }^{1}$; Aron J. Hall, DVM ${ }^{1}$; Neil Gupta, MD ${ }^{1}$; Wendi L. Kuhnert, PhD ${ }^{1}$; Paula W. Yoon, ScD ${ }^{1}$; Adi V. Gundlapalli, MD, PhD ${ }^{1}$; Michael J. Beach, PhD ${ }^{1}$; Henry T. Walke, $\mathrm{MD}^{1}$; CDC COVID-19 Response Team
\end{abstract}

On December 4, 2020, this report was posted as an MMWR Early Release on the MMWR website (https://www.cdc.gov/mmwr).

In the 10 months since the first confirmed case of coronavirus disease 2019 (COVID-19) was reported in the United States on January 20, 2020 (1), approximately 13.8 million cases and 272,525 deaths have been reported in the United States. On October 30, the number of new cases reported in the United States in a single day exceeded 100,000 for the first time, and by December 2 had reached a daily high of 196,227.* With colder weather, more time spent indoors, the ongoing U.S. holiday season, and silent spread of disease, with approximately $50 \%$ of transmission from asymptomatic persons (2), the United States has entered a phase of high-level transmission where a multipronged approach to implementing all evidence-based public health strategies at both the individual and community levels is essential. This summary guidance highlights critical evidence-based CDC recommendations and sustainable strategies to reduce COVID-19 transmission. These strategies include 1) universal face mask use, 2) maintaining physical distance from other persons and limiting in-person contacts, 3) avoiding nonessential indoor spaces and crowded outdoor spaces, 4) increasing testing to rapidly identify and isolate infected persons, 5) promptly identifying, quarantining, and testing close contacts of persons with known COVID-19, 6) safeguarding persons most at risk for severe illness or death from infection with SARS-CoV-2, the virus that causes COVID-19, 7) protecting essential workers with provision of adequate personal protective equipment and safe work practices, 8) postponing travel, 9) increasing room air ventilation and enhancing hand hygiene and environmental disinfection, and 10) achieving widespread availability and high community coverage with effective COVID-19 vaccines. In combination, these strategies can reduce SARS-CoV-2 transmission, long-term sequelae or disability, and death, and mitigate the pandemic's economic impact. Consistent implementation of these strategies improves health equity, preserves health care capacity, maintains the function of essential businesses, and supports the availability of in-person instruction for kindergarten through grade 12 schools and preschool. Individual persons, households, and communities should take

\footnotetext{
${ }^{*}$ https://covid.cdc.gov/covid-data-tracker/\#trends_dailytrendscases.
}

these actions now to reduce SARS-CoV-2 transmission from its current high level. These actions will provide a bridge to a future with wide availability and high community coverage of effective vaccines, when safe return to more everyday activities in a range of settings will be possible.

\section{Recommended Public Health Strategies}

Universal use of face masks. Consistent and correct use of face masks is a public health strategy critical to reducing respiratory transmission of SARS-CoV-2, particularly in light of estimates that approximately one half of new infections are transmitted by persons who have no symptoms $(2,3)$. Compelling evidence now supports the benefits of cloth face masks for both source control (to protect others) and, to a lesser extent, protection of the wearer. ${ }^{\dagger}$ To preserve the supply of N95 respirators for health care workers and other medical first responders, $\mathrm{CDC}$ recommends nonvalved, multilayer cloth masks or nonmedical disposable masks for community use. ${ }^{\S}$ Face mask use is most important in indoor spaces and outdoors when physical distance of $\geq 6$ feet cannot be maintained. Within households, face masks should be used when a member of the household is infected or has had recent potential COVID-19 exposure (e.g., known close contact or potential exposure related to occupation, crowded public settings, travel, or nonhousehold members in your house). A community-level plan for distribution of face masks to specific populations, such as those who might experience barriers to access, should be developed (Table).

Physical distancing and limiting contacts. Maintaining physical distance ( $\geq 6$ feet) lowers the risk for SARS-CoV-2 infection through exposure to infectious respiratory droplets and aerosols and is important, even if no symptoms are apparent, because transmission can occur from asymptomatic infected persons $(2,3)$. Outside the household setting, close physical contact, shared meals, and being in enclosed spaces have all been associated with an increased infection risk (4-7). Although the impact of physical distancing is difficult to disaggregate from other interventions, one study estimated that physical distancing decreased the average number of daily

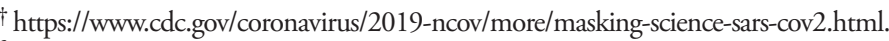
${ }^{\$}$ https://www.cdc.gov/coronavirus/2019-ncov/prevent-getting-sick/cloth-facecover-guidance.html.

Sttps://www.cdc.gov/coronavirus/2019-ncov/prevent-getting-sick/socialdistancing.html.
} 
TABLE. Individual- and community-level public health strategies to reduce SARS-CoV-2 transmission*

\begin{tabular}{|c|c|}
\hline $\begin{array}{l}\text { Recommended public } \\
\text { health strategies }\end{array}$ & $\begin{array}{c}\text { Individual- and } \\
\text { household-level strategies }\end{array}$ \\
\hline Universal use of face masks & $\begin{array}{l}\text { Consistent and correct use of face } \\
\text { masks, including within the } \\
\text { household if there is a COVID-19 } \\
\text { case or a person with a known or } \\
\text { possible exposure in the household } \mathrm{P}\end{array}$ \\
\hline
\end{tabular}

Community-level strategies (at state or local level)

Links to guidance

Physical distancing and limiting contacts
Avoid nonessential indoor spaces and crowded outdoor settings
Issue policies or directives mandating universal use of face masks in indoor (nonhousehold) settings

Plan for provision of face masks for specific populations if needed
Maintain physical distance ( $\geq 6$ feet) from other persons when possible, and limit number of contacts with persons outside the immediate household

Avoid nonessential indoor spaces and crowded outdoor settings
Physical barriers and visual reminders maintaining physical distance might promote adherence to

Considerations for wearing masks: https://www.cdc. gov/coronavirus/2019-ncov/prevent-getting-sick/ cloth-face-cover-guidance.html

Caring for someone sick at home, when to wear a mask or gloves: https://www.cdc.gov/ coronavirus/2019-ncov/if-you-are-sick/care-forsomeone.html\#face-covering

Protect your home: https://www.cdc.gov/ coronavirus/2019-ncov/prevent-getting-sick/ protect-your-home.htm

Social distancing: https://www.cdc.gov/ coronavirus/2019-ncov/prevent-getting-sick/ social-distancing.html

Personal and social activities: https://www.cdc.gov/ coronavirus/2019-ncov/daily-life-coping/personalsocial-activities.html

Daily activities and going out: https://www.cdc.gov/

Issue policies or directives restricting some nonessential indoor spaces that pose the highest risk for transmission

Promoting flexible worksites (e.g., telework); apply limits to occupancy of indoor spaces and to the size of social gatherings

Increase access to testing, including expanded screening testing of prioritized persons/groups, prioritizing those with many interactions (or interactions with persons at high risk) based on their occupational or residential setting promptly seek testing symptomatic or infected persons should isolate promptly; exposed persons should quarantine

Considerations for events and gatherings: https://www. cdc.gov/coronavirus/2019-ncov/community/ large-events/considerations-for-events-gatherings.html

Testing: https://www.cdc.gov/coronavirus/2019ncov/testing/index.html

Expanded screening testing: https://www.cdc.gov/ coronavirus/2019-ncov/php/open-america/ expanded-screening-testing.html

Isolate if you are sick: https://www.cdc.gov/
Promptly report test results to the person tested and to public health authorities coronavirus/2019-ncov/if-you-are-sick/isolation.html

Guidance for health departments about COVID-19 testing in the community: https://www.cdc.gov/ coronavirus/2019-ncov/php/open-america/testing.html

When to quarantine: https://www.cdc.gov/

When incidence is high and overwhelms capacity, prioritize case investigation and contact tracing to promptly quarantine and test close contacts, based on time since sample collection and risk for spread to others (e.g., those working in high-density settings) coronavirus/2019-ncov/if-you-are-sick/quarantine.html

Contact tracing (your health): https://www.cdc.gov/ coronavirus/2019-ncov/daily-life-coping/contacttracing.html adhere to quarantine, seek testing and encourage their household members to quarantine
Contact tracing (health departments): https://www. cdc.gov/coronavirus/2019-ncov/php/open-america/ contact-tracing/index.html

Prioritizing case investigation and contact tracing: https:// www.cdc.gov/coronavirus/2019-ncov/php/contacttracing/contact-tracing-plan/prioritization.html

Quarantine: https://www.cdc.gov/coronavirus/2019-ncov/ more/scientific-brief-options-to-reduce-quarantine.html

People at increased risk: https://www.cdc.gov/

Protect persons most at risk for severe illness or death through 1) identifying populations at high risk in the community and 2) expanding access to testing, provision of support services, and messaging index.htm at risk for severe illness or death them at increased risk for severe illness or death should minimize contact with nonhousehold members and nonessential indoor spaces
Persons with underlying medical

See table footnotes on the next page. 
TABLE. (Continued) Individual- and community-level public health strategies to reduce SARS-CoV-2 transmission*

\section{Recommended public} health strategies

Protecting essential workers

\section{Individual-and} household-level strategies
Community-level strategies (at state or local level)
Links to guidance
Essential workers should employ all Protect essential workers through available public health strategies to reduce their risk (e.g., wear face masks and keep physical distance) policies directing administrative and structural prevention as well as expanded testing
Postponing travel
Travel should be postponed. Those who choose to travel internationally should be tested with a viral test 1-3 days before departure and retested 3-5 days after arrival; domestic travelers should also consider getting tested

Travelers should stay home or reduce nonessential activities before and after travel and be diligent about mask wearing, physical distancing, hand hygiene, and symptom monitoring
Increased room air ventilation, Increase room air ventilation enhanced hand hygiene, and cleaning and disinfection
Issue policies or directives mandating universal use of face masks on all modes of public transportation
Essential services and critical infrastructure: https:// www.cdc.gov/coronavirus/2019-ncov/community/ workplaces-businesses/essential-services.html

COVID-19 critical infrastructure sector response planning: https://www.cdc.gov/coronavirus/2019ncov/community/critical-infrastructure-sectors.html

CISA guidance on the essential critical infrastructure workforce: https://www.cisa.gov/publication/ guidance-essential-critical-infrastructure-workforce

Travel: https://www.cdc.gov/coronavirus/2019-ncov/ travelers/index.html
When not to travel: https://www.cdc.gov/ coronavirus/2019-ncov/travelers/when-to-delaytravel.html

Wear face masks on public transportation conveyances and at transportation hubs: https:// www.cdc.gov/coronavirus/2019-ncov/travelers/ face-masks-public-transportation.html

Mask and travel guidance: https://www.cdc.gov/ quarantine/masks/mask-travel-guidance.html

Domestic travel: https://www.cdc.gov/ coronavirus/2019-ncov/travelers/travel-duringcovid19.html

Testing and international air travel: https://www.cdc. gov/coronavirus/2019-ncov/travelers/testing-airtravel.html

Enhance ventilation and cleaning and disinfection, particularly of essential indoor spaces

Ensure provision of adequate hand sanitation supplies

SARS-CoV-2 and potential airborne transmission: https://www.cdc.gov/coronavirus/2019-ncov/more/ scientific-brief-sars-cov-2.html

Ventilation: https://www.cdc.gov/coronavirus/2019ncov/community/general-business-faq. html\#Ventilation

When and how to wash your hands: https://www.cdc. gov/handwashing/when-how-handwashing.html

Cleaning and disinfecting: https://www.cdc.gov/ coronavirus/2019-ncov/community/clean-disinfect/ index.html

Vaccines: https://www.cdc.gov/coronavirus/2019-

Plan for distribution and ncov/vaccines/index.htm

high community coverage

Communicate that mitigation measures still need to be followed until

Vaccination planning: https://www.cdc.gov/vaccines/

Continue to follow all mitigation measures until community vaccination coverage is adequate community vaccination coverage is determined to be adequate

Abbreviations: ACIP = Advisory Committee on Immunization Practices; COVID-19 = coronavirus disease 2019.

* https://www.cdc.gov/coronavirus/2019-ncov/communication/guidance-list.html. 
contacts by as much as $74 \%$ and reduced the reproductive number $\left(\mathrm{R}_{0}\right.$, a measure of transmission, which describes the average number of persons infected by one infectious person) to $<1(8)$. Because the highest risk for transmission has been documented among household contacts of COVID-19 patients (9), keeping the household safe requires physical distancing, using the other public health strategies summarized here, and, in particular, consistent and correct use of face masks (outside the household and in some circumstances within the household) to prevent introduction and transmission of SARS-CoV-2. At the community level, physical barriers and visual reminders might promote adherence to maintaining physical distance.

Avoiding nonessential indoor spaces and crowded outdoor settings. Exposures at nonessential indoor settings and crowded outdoor settings pose a preventable risk to all participants. ${ }^{* *}, \dagger$ Indoor venues, where distancing is not maintained and consistent use of face masks is not possible (e.g., restaurant dining), have been identified as particularly high-risk scenarios $(7,10)$. Crowded events in outdoor settings have also been linked to spread of SARS-CoV-2, although it can be difficult to isolate the impact of crowded outdoor events from related indoor social interactions (11). To reduce risk, some restaurants are providing take-away service and well-ventilated open-air dining, and in many cases, exercise or physical activity (individual or group) can be moved to outdoor settings where physical distance is maintained and face masks are worn. Community-level policies can further reduce transmission by promoting flexible worksites (e.g., telework) and hours, as well as by applying limits to occupancy of indoor spaces and to the size of social gatherings.

Increased testing, diagnosis, and isolation. Isolation is used to separate persons infected with SARS-CoV-2 from those who are not infected; persons who are identified by testing to be infected should be rapidly isolated. ${ }^{\$}$ Estimates vary, however, $>40 \%$ of persons infected with SARS-CoV-2 might be asymptomatic, and transmission from presymptomatic persons (those who are not symptomatic at the time they transmit infection, but who later experience symptoms) and asymptomatic persons (infected persons who never experience symptoms) is estimated to account for $>50 \%$ of all transmission $(2,3)$. Therefore, reliance on symptom screening to identify infected persons is inadequate (12). Increased testing is an important strategy to interrupt silent transmission of SARS-CoV-2 from asymptomatic and presymptomatic persons. However, because the sensitivity of available tests and the time since exposure varies, a negative test might provide false reassurance; thus, all

\footnotetext{
** https://www.cdc.gov/coronavirus/2019-ncov/community/large-events/ considerations-for-events-gatherings.html.

$\dagger \dagger$ https://www.cdc.gov/coronavirus/2019-ncov/daily-life-coping/going-out.html.

$\$ \$$ https://www.cdc.gov/coronavirus/2019-ncov/if-you-are-sick/isolation.html.
}

prevention strategies should continue to be followed including use of face masks and maintaining physical distance. A comparative analysis of data from six large countries demonstrated that high levels of testing, combined with robust contact tracing, can substantially reduce the transmission of SARS-CoV-2 (13). Frequent testing and contact tracing, combined with other mitigation measures, effectively limited SARS-CoV-2 transmission on a college campus (14). In addition to testing symptomatic persons and those with known exposure, a strategy of routinely testing certain population groups with high numbers of interactions with other persons, based on their occupational or residential setting, can more rapidly identify asymptomatic and presymptomatic infectious persons and their close contacts for isolation and quarantine.99 Communities with high or increasing SARS-CoV-2 transmission should increase screening testing, focusing on persons at increased risk for exposure (e.g., workers in high-density worksites) or persons who might have the potential to transmit infection to large numbers of other persons (e.g., persons working in congregate settings) or to transmit to persons at risk for severe COVID-19-associated illness or death (e.g., staff members in nursing homes). Expanded screening testing should be implemented in a manner that promotes health equity for persons with limited resources or other barriers to accessing health care. In addition, prompt reporting of test results to the person tested and to public health authorities can facilitate rapid isolation, case investigation and contact tracing, and accurate monitoring of COVID-19 in the community.

Prompt case investigation and contact tracing to identify, quarantine, and test close contacts. Case investigation is the process of obtaining comprehensive information about persons with a diagnosis of COVID-19 and is followed by contact tracing, which includes identifying and communicating with persons exposed to SARS-CoV-2 (i.e., close contacts***) to inform them of their exposure, educate them about risks for and symptoms of COVID-19, and encourage them to quarantine, seek testing, and monitor themselves for signs or symptoms of illness. ${ }^{\dagger \dagger}$ Quarantine is used to keep a person who was exposed to SARS-CoV-2 away from others. $\$ \$ \$$ Contact tracing is most feasible when the incidence of COVID-19 in the community or workplace is low or declining, when testing and reporting of results can occur quickly (15), and when most contacts can be reached and quarantined (16). When one or more of these conditions is not met or when local capacity is

\footnotetext{
I9 https://www.cdc.gov/coronavirus/2019-ncov/php/open-america/expandedscreening-testing.html.

*** https://www.cdc.gov/coronavirus/2019-ncov/php/contact-tracing/contacttracing-plan/appendix.html\#contact.

$t^{\dagger \dagger}$ https://www.cdc.gov/coronavirus/2019-ncov/daily-life-coping/contacttracing.html.

$\$ \$ \$$ https://www.cdc.gov/coronavirus/2019-ncov/if-you-are-sick/quarantine.html.
} 
overwhelmed, health departments should narrow the scope of contact tracing activities and emphasize community mitigation measures. Investigations should prioritize persons who most recently received positive SARS-CoV-2 test results, as well as identify and quarantine household contacts and persons exposed in a congregate living facility, high-density workplace, or other setting (or event) with potential extensive transmission. 999 Because the risk for household transmission is high and occurs rapidly in the absence of face masks or other protective behaviors, household members of persons with diagnosed COVID-19 should be quarantined, and, in the event that they experience symptoms or receive a positive test result, they should be isolated $(9,17)$. Eliciting and reaching contacts in a timely manner is challenging $(18,19)$, and quarantine can impose economic and financial burdens (20); adherence to quarantine might require provision of appropriate support services. ${ }^{* * * *}$ Persons who receive positive SARS-COV-2 test results should also be encouraged to serve as their own contact tracers by informing close contacts that they have been exposed and encouraging those persons to quarantine, monitor for symptoms, and seek testing.

Safeguarding persons most at risk for severe illness or death. To protect those who are at highest risk for severe COVID-19-associated outcomes, universal mitigation efforts are needed. SARS-CoV-2 infection can be completely asymptomatic or can manifest as a life-threatening illness; disease can result in postacute and long-term sequelae or disability among survivors. Risk for severe illness increases with age and is highest for those aged $\geq 85$ years. ${ }^{\dagger \dagger \dagger}$ In the United States, approximately $80 \%$ of reported COVID-19 deaths have occurred in patients aged $\geq 65$ years.

Certain underlying medical conditions also increase risk for severe illness or death for persons of any age with COVID-19. $\$ \$ \$ \$$ Long-term care facilities serve older adults and persons with complex medical conditions; COVID-19 can spread rapidly in these congregate settings, resulting in high rates of morbidity and mortality. To prevent introduction and transmission of SARS-CoV-2, these facilities should implement strict infection prevention and control measures and expanded screening testing of both staff members and residents to rapidly identify and isolate infected persons. 9999

\footnotetext{
999 https://www.cdc.gov/coronavirus/2019-ncov/php/contact-tracing/contacttracing-plan/prioritization.html.

**** https://www.cdc.gov/coronavirus/2019-ncov/php/contact-tracing/contacttracing-plan/support-services.html.

$\dagger^{\dagger}+\dagger$ https://www.cdc.gov/coronavirus/2019-ncov/need-extra-precautions/olderadults.html.

$\$ \$ \$ \$$ https://www.cdc.gov/coronavirus/2019-ncov/need-extra-precautions/ people-with-medical-conditions.html.

9999 https://www.cdc.gov/coronavirus/2019-ncov/hcp/nursing-home-longterm-care.html.
}

COVID-19 has also disproportionately affected racial and ethnic minority groups. ${ }^{* * * * *}$ An age-standardized analysis of COVID-19-associated deaths reported to the National Vital Statistics System through November 25, 2020, found that Black persons accounted for $26.9 \%$ of COVID-19-related deaths, despite representing $12.7 \%$ of the U.S. population. ${ }^{\dagger \dagger \dagger \dagger \dagger}$ Persons who belong to racial or ethnic minority groups are likewise disproportionately affected by the underlying medical conditions that increase risk for severe COVID-19 illness and death, likely because of long-standing inequities in social determinants of health. Members of racial or ethnic minority groups are more likely to experience lower socioeconomic status, to live in crowded housing, and possibly to be employed in occupations that require in-person work. $\$ \$ \$ \$ \$ S$ In addition, access to health care might be limited, including obtaining testing and care for COVID-19.

Persons who are at highest risk for severe COVID-19-associated illness or death or who share a household with someone at high risk should minimize their individual and household risk by avoiding nonessential interactions with persons outside their household whenever possible and implementing all recommended public health prevention strategies. Some approaches to safeguarding those with underlying medical conditions include promoting access to and use of telehealth when feasible and appropriate, use of no-contact pickup for groceries or other essential items, and use of online (versus in-person) educational instruction.

Protecting essential workers. Essential (critical infrastructure) workers include health care personnel and employees in other essential workplaces (e.g., first responders and grocery store workers). 99999 Protecting essential workers requires full implementation of all evidence-based strategies outlined in this guidance. When a COVID-19 vaccine is authorized for use by the Food and Drug Administration (FDA) and recommended by the Advisory Committee on Immunization Practices (ACIP), essential workers, including health care personnel, are among the populations being considered for initial phased allocation of limited vaccine doses (21). Implementation of infection prevention and control with adequate supplies and extensive use of telehealth options and nurse-directed triage of patients, as well as screening of all persons entering health care facilities for signs and symptoms of COVID-19, can protect health care personnel and reduce risk for SARS-CoV-2 transmission in health care facilities.****** U.S. food manufacturing

\footnotetext{
***** https://www.cdc.gov/coronavirus/2019-ncov/community/health-equity/ race-ethnicity.html.

†t† ht† https://www.cdc.gov/nchs/nvss/vsrr/covid19/health_disparities.htm.

$\$ \$ \$ \$ \$$ https://www.census.gov/content/dam/Census/programs-surveys/ahs/ publications/Measuring_Overcrowding_in_Hsg.pdf.

99995 t t p s : / / w w w. c i s a.g o v/ p u b l i c a t i o n/ guidance-essential-critical-infrastructure-workforce.

****** https:/www.cdc.gov/coronavirus/2019-ncov/hcp/infection-controlrecommendations.html.
} 
and agriculture is another sector that has been substantially affected by COVID-19, especially among workers in meat and poultry processing facilities, with disproportionate effects among persons who belong to racial or ethnic minority groups (22). CDC and the Occupational Safety and Health Administration released guidance on administrative and engineering controls that should be part of COVID-19 assessment and control plans for these workplaces. ${ }^{1 \dagger \dagger \dagger \dagger \dagger}$ When cessation of operation of a facility might cause serious harm or danger to public health or safety, essential workers who are known close contacts of persons with confirmed COVID-19 might need to return to work as a last resort; however, if they return to work, they should use face masks and maintain physical distancing, and the workplace should be appropriately disinfected. $\$ \$ \$ \$ S \$$ These persons should only return to work if they are and remain asymptomatic and undergo at least daily active symptom monitoring with immediate removal from the workplace if any signs or symptoms of possible COVID-19 occur; viral testing of all close contacts is recommended, and those with positive test results should not return to work.

Postponing travel. Travel increases the likelihood of SARS-CoV-2 exposure and infection and could translocate infection between communities. Postponing travel is the best way to reduce this risk.99999 Any traveler who is symptomatic, has had close contact with a person with COVID-19 and has not met criteria for release from quarantine, or has a positive or pending SARS-CoV-2 test result should not travel. ${ }^{* * * * * * *}$ For those contemplating international travel, CDC recommends getting tested with a viral test for SARS-CoV-2 1-3 days before departure and getting retested 3-5 days after arrival. ${ }^{\dagger+\dagger^{\dagger}+\dagger \dagger}$ Domestic travelers should also consider testing. Testing does not eliminate all risk and should be combined with other recommended public health strategies. Both domestic and international travelers should stay home or reduce nonessential activities before travel, and for 7 days after travel if tested, even if test results are negative. If not tested, this period should be extended to 10 days. Travelers should be diligent about mask wearing, physical distancing, hand hygiene, and symptom monitoring. For 14 days after arrival, travelers should avoid close contact with persons at higher risk for severe COVID-19-associated outcomes and wear masks in household spaces shared with those who did not travel.

\footnotetext{
$\dagger_{\dagger \dagger \dagger \dagger \dagger}$ https://www.cdc.gov/coronavirus/2019-ncov/community/organizations/ meat-poultry-processing-workers-employers.html.

$\$ \$ S \$ S \$$ https://www.cdc.gov/coronavirus/2019-ncov/community/criticalinfrastructure-sectors.html?CDC_AA_refVal.

99999 https://www.cdc.gov/coronavirus/2019-ncov/travelers/travel-duringcovid19.html.

*******https://www.cdc.gov/coronavirus/2019-ncov/travelers/when-to-delaytravel.html.

${ }^{\dagger}+\dagger_{\dagger+1 \dagger}$ https://www.cdc.gov/coronavirus/2019-ncov/travelers/testing-air-travel.html.
}

Increased room air ventilation, enhanced hand hygiene, and cleaning and disinfection. Increasing room air ventilation, enhancing hand hygiene, and cleaning and disinfecting frequently touched surfaces might help decrease transmission of SARS-CoV-2 (23). ${ }^{\$ S \$ S \$ S \$}$ Although the epidemiology of SARS-CoV-2 suggests that most transmission is close person-to-person, there have been some documented cases of presumed airborne transmission.999999 Avoiding nonessential indoor spaces can help reduce this risk. For indoor settings, increased room air ventilation can decrease the concentration of small droplets and particles carrying infectious virus suspended in the air and, thereby, presumably decrease the risk for transmission. ${ }^{* * * * * * * *}$ Hand hygiene includes handwashing with soap and water or using alcohol-based hand sanitizer. ${ }^{\dagger \dagger \dagger \dagger \dagger \dagger \dagger}$ Handwashing mechanically removes pathogens, and laboratory data demonstrate that hand sanitizers that contain at least $60 \%$ alcohol inactivate SARS-CoV-2 (24). These strategies, combined with appropriate cleaning and disinfection of surfaces, might prevent indirect transmission through touching surfaces contaminated with virus from an infected person, followed by touching the mouth, nose, or eyes.

Widespread availability and use of effective vaccines. Widespread availability and high community coverage with safe and effective COVID-19 vaccines represent the most important public health strategy to control the pandemic. Many COVID-19 vaccine candidates are currently in clinical trials. Promising products are being manufactured in anticipation of Emergency Use Authorization from the FDA. The federal government has established a centralized system to order, distribute, and track COVID-19 vaccines through states, tribal nations, and territories; these jurisdictions are preparing for vaccination with extensive planning for vaccine distribution and administration. $\$ \$ S \$ S \$$ After FDA authorization of the use of one or more COVID-19 vaccines in the United States, the ACIP will review safety and efficacy data for each of the authorized vaccines and will issue recommendations for use to ensure equitable access $(21,25)$. Ensuring transparency in these efforts, monitoring for adverse events, and working with communities to address concerns will be critical to obtaining the confidence and trust of the public and health care providers. CDC and FDA will monitor the effectiveness and safety of all COVID-19 vaccines and update and communicate this information regularly. Vaccinated persons should continue

\footnotetext{
\$\$S\$S\$S https://www.cdc.gov/coronavirus/2019-ncov/community/cleandisinfect/index.html.

9999999 https://www.cdc.gov/coronavirus/2019-ncov/more/scientific-brief-sarscov-2.html.

******** https://www.cdc.gov/niosh/conferences/events/heatventair.html.

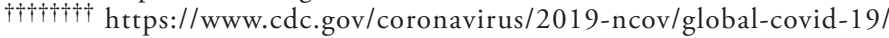
handwashing.html.

\$S\$S\$S\$ https://www.cdc.gov/vaccines/covid-19/planning/index.html.
} 


\section{Summary}

What is already known about this topic?

The United States is experiencing high levels of SARS-CoV-2 transmission.

What is added by this report?

COVID-19 pandemic control requires a multipronged application of evidence-based strategies while improving health equity: universal face mask use, physical distancing, avoiding nonessential indoor spaces, increasing testing, prompt quarantine of exposed persons, safeguarding those at increased risk for severe illness or death, protecting essential workers, postponing travel, enhancing ventilation and hand hygiene, and achieving widespread COVID-19 vaccination coverage.

What are the implications for public health practice?

These combined strategies will protect health care, essential businesses, and schools, bridging to a future with high community coverage of effective vaccines and safe return to more activities in a range of settings.

to adhere to all mitigation measures (e.g., mask use, physical distancing, and hand hygiene) until both doses in the series have been received and the duration of immunity provided by vaccines has been sufficiently established.

\section{Discussion}

No single strategy can control the pandemic; rather, a multipronged approach using all available evidence-based strategies at the individual and community levels can break transmission chains and address high levels of community transmission; reduce related illnesses, long-term sequelae, and deaths; and mitigate the pandemic's economic impact. Because COVID-19 has disproportionately affected persons with certain risk factors (e.g., age and some underlying medical conditions) and racial/ ethnic minorities, implementing public health prevention strategies in a manner that assures health equity is imperative to safeguard those who have borne the worst of the pandemic's impact. The U.S. health care system is being stressed by COVID-19, with multiple jurisdictions establishing expanded or alternative treatment settings. Continuing mitigation efforts will be essential to preserve capacity for adequate treatment of persons with COVID-19 and other urgent health conditions, and to protect essential and preventive services that are not amenable to telehealth. Schools provide numerous benefits beyond education, including school meal programs and social, physical, behavioral, and mental health services. Because of their critical role for all children and the disproportionate impact that school closures can have on those with the least economic means, kindergarten through grade 12 schools should be the last settings to close after all other mitigation measures have been employed and the first to reopen when they can do so safely. 99999999 Similarly, full implementation of public health prevention strategies can help preserve the functioning of essential businesses that supply food to the population, contribute to the health protection of communities and individual persons, and fuel economic recovery. Full implementation of and adherence to these strategies will save lives. As communities respond to high levels of SARS-CoV-2 transmission, these strategies will also provide the necessary bridge to a future with wide availability and high levels of coverage with effective vaccines, and thereby a safe return to more everyday activities in a range of settings.

S999999 https://www.cdc.gov/coronavirus/2019-ncov/community/schools-
childcare/indicators.html.

\section{Acknowledgments}

CDC's state, tribal, local, and territorial health department partners and CDC staff members supporting the COVID-19 response.

\section{CDC COVID-19 Response Team}

Eduardo Azziz-Baumgartner, CDC; Sarah Bennett, CDC; Chris Braden, CDC; Jennifer Buigut, CDC; Tom Chiller, CDC; Cindy R. Friedman, CDC; Carolyn M. Greene, CDC; Olga Henao, CDC; Christine Kosmos, CDC; Adam MacNeil, CDC; Barbara Marston, CDC; Greta Massetti, CDC; Jose Montero, CDC; Cria G. Perrine, CDC; Kara Polen, CDC; Karen Remley, CDC; Reynolds Salerno, CDC; Kelly A. Shaw, CDC; Ian Williams, CDC.

Corresponding author: Margaret A. Honein, mrh7@cdc.gov.

${ }^{1}$ CDC COVID-19 Emergency Response.

All authors have completed and submitted the International Committee of Medical Journal Editors form for disclosure of potential conflicts of interest. No potential conflicts of interest were disclosed.

\section{References}

1. Holshue ML, DeBolt C, Lindquist S, et al.; Washington State 2019-nCoV Case Investigation Team. First case of 2019 novel coronavirus in the United States. N Engl J Med 2020;382:929-36. PMID:32004427 https:// doi.org/10.1056/NEJMoa2001191

2. Moghadas SM, Fitzpatrick MC, Sah P, et al. The implications of silent transmission for the control of COVID-19 outbreaks. Proc Natl Acad Sci U S A 2020;117:17513-5. PMID:32632012 https://doi. org/10.1073/pnas.2008373117

3. Lavezzo E, Franchin E, Ciavarella C, et al.; Imperial College COVID-19 Response Team. Suppression of a SARS-CoV-2 outbreak in the Italian municipality of Vo'. Nature 2020;584:425-9. PMID:32604404 https:// doi.org/10.1038/s41586-020-2488-1

4. Park SY, Kim YM, Yi S, et al. Coronavirus disease outbreak in call center, South Korea. Emerg Infect Dis 2020;26:1666-70. PMID:32324530 https://doi.org/10.3201/eid2608.201274

5. Hamner L, Dubbel P, Capron I, et al. High SARS-CoV-2 attack rate following exposure at a choir practice-Skagit County, Washington, March 2020. MMWR Morb Mortal Wkly Rep 2020;69:606-10. PMID:32407303 https://doi.org/10.15585/mmwr.mm6919e6 
6. Jang S, Han SH, Rhee JY. Cluster of coronavirus disease associated with fitness dance classes, South Korea. Emerg Infect Dis 2020;26:1917-20. PMID:32412896 https://doi.org/10.3201/eid2608.200633

7. Fisher KA, Tenforde MW, Feldstein LR, et al.; IVY Network Investigators; CDC COVID-19 Response Team. Community and close contact exposures associated with COVID-19 among symptomatic adults $\geq 18$ years in 11 outpatient health care facilities_-United States, July 2020. MMWR Morb Mortal Wkly Rep 2020;69:1258-64. PMID:32915165 https://doi.org/10.15585/mmwr.mm6936a5

8. Jarvis CI, Van Zandvoort K, Gimma A, et al.; CMMID COVID-19 working group. Quantifying the impact of physical distance measures on the transmission of COVID-19 in the UK. BMC Med 2020;18:124. PMID:32375776 https://doi.org/10.1186/s12916-020-01597-8

9. Grijalva CG, Rolfes MA, Zhu Y, et al. Transmission of SARS-COV-2 infections in households-Tennessee and Wisconsin, April-September 2020. MMWR Morb Mortal Wkly Rep 2020;69:1631-4. PMID:33151916 https://doi.org/10.15585/mmwr.mm6944e1

10. Chang S, Pierson E, Koh PW, et al. Mobility network models of COVID-19 explain inequities and inform reopening. Nature 2020.Epub November 10, 2020. PMID:33171481 https://doi.org/10.1038/ s41586-020-2923-3

11. Sassano M, McKee M, Ricciardi W, Boccia S. Transmission of SARS-CoV-2 and other infections at large sports gatherings: a surprising gap in our knowledge. Front Med (Lausanne) 2020;7:277. PMID:32574343 https://doi.org/10.3389/fmed.2020.00277

12. Poline J, Gaschignard J, Leblanc C, et al. Systematic SARS-CoV-2 screening at hospital admission in children: a French prospective multicenter study. Clin Infect Dis 2020;ciaa1044. PMID:32710743 https://doi.org/10.1093/cid/ciaa1044

13. Chen YT, Yen YF, Yu SH, Su EC. An examination on the transmission of COVID-19 and the effect of response strategies: a comparative analysis. Int J Environ Res Public Health 2020;17:5687. https://doi. org/10.3390/ijerph 17165687

14. Denny TN, Andrews L, Bonsignori M, et al. Implementation of a pooled surveillance testing program for asymptomatic SARS-CoV-2 infections on a college campus - Duke University, Durham, North Carolina, August 2October 11, 2020. MMWR Morb Mortal Wkly Rep 2020;69:1743-7. PMID:33211678 https://doi.org/10.15585/mmwr.mm6946e1

15. Kretzschmar ME, Rozhnova G, Bootsma MCJ, van Boven M, van de Wijgert JHHM, Bonten MJM. Impact of delays on effectiveness of contact tracing strategies for COVID-19: a modelling study. Lancet Public Health 2020;5:e452-9. PMID:32682487 https://doi. org/10.1016/S2468-2667(20)30157-2
16. Bilinski A, Mostashari F, Salomon JA. Modeling contact tracing strategies for COVID-19 in the context of relaxed physical distancing measures. JAMA Netw Open 2020;3:e2019217. PMID:32821920 https://doi. org/10.1001/jamanetworkopen.2020.19217

17. Lewis NM, Chu VT, Ye D, et al. Household transmission of SARS-CoV-2 in the United States. Clin Infect Dis 2020. Epub August 16, 2020. PMID:33185244 https://doi.org/10.1093/cid/ciaa1166

18. Lash RR, Donovan CV, Fleischauer AT, et al.; Contact Tracing Assessment Team. COVID-19 contact tracing in two counties-North Carolina, June-July 2020. MMWR Morb Mortal Wkly Rep 2020;69:1360-3. PMID:32970654 https://doi.org/10.15585/mmwr.mm6938e3

19. Kanu FA, Smith EE, Offutt-Powell T, Hong R, Dinh TH, Pevzner E; Delaware Case Investigation and Contact Tracing Teams. Declines in SARS-CoV-2 transmission, hospitalizations, and mortality after implementation of mitigation measures_Delaware, March-June 2020. MMWR Morb Mortal Wkly Rep 2020;69:1691-4. PMID:33180757 https://doi.org/10.15585/mmwr.mm6945e1

20. Bodas M, Peleg K. Self-isolation compliance in the COVID-19 era influenced by compensation: findings from a recent survey in Israel. Health Aff (Millwood) 2020;39:936-41. PMID:32271627 https://doi. org/10.1377/hlthaff.2020.00382

21. McClung N, Chamberland M, Kinlaw K, et al. The Advisory Committee on Immunization Practices' ethical principles for allocating initial supplies of COVID-19 vaccine-United States, 2020. MMWR Morb Mortal Wkly Rep 2020;69:1782-6. PMID:33237895 https://doi. org/10.15585/mmwr.mm6947e3

22. Waltenburg MA, Rose CE, Victoroff T, et al.; CDC COVID-19 Emergency Response Team. Coronavirus disease among workers in food processing, food manufacturing, and agriculture workplaces. Emerg Infect Dis 2020;27:27. PMID:33075274

23. Aiello AE, Coulborn RM, Perez V, Larson EL. Effect of hand hygiene on infectious disease risk in the community setting: a meta-analysis. Am J Public Health 2008;98:1372-81. PMID:18556606 https://doi. org/10.2105/AJPH.2007.124610

24. Kratzel A, Todt D, V'kovski P, et al. Inactivation of severe acute respiratory syndrome coronavirus 2 by WHO-recommended hand rub formulations and alcohols. Emerg Infect Dis 2020;26:1592-5. PMID:32284092 https://doi.org/10.3201/eid2607.200915

25. Dooling K, McClung N, Chamberland M, et al. The Advisory Committee on Immunization Practices' interim recommendation for allocating initial supplies of COVID-19 vaccine-United States, 2020. MMWR Morb Mortal Wkly Rep 2020;69. Epub December 3, 2020. 